\title{
Validating the WHO maternal near miss tool: comparing high- and low-resource settings
}

Tom Witteveen ${ }^{1 *}$ (D), Hans Bezstarosti ${ }^{1}$, Ilona de Koning ${ }^{1}$, Ellen Nelissen ${ }^{2}$, Kitty W. Bloemenkamp ${ }^{1,3}$, Jos van Roosmalen ${ }^{1,4}$ and Thomas van den Akker $^{1}$

\begin{abstract}
Background: WHO proposed the WHO Maternal Near Miss (MNM) tool, classifying women according to several (potentially) life-threatening conditions, to monitor and improve quality of obstetric care. The objective of this study is to analyse merged data of one high- and two low-resource settings where this tool was applied and test whether the tool may be suitable for comparing severe maternal outcome (SMO) between these settings.

Methods: Using three cohort studies that included SMO cases, during two-year time frames in the Netherlands, Tanzania and Malawi we reassessed all SMO cases (as defined by the original studies) with the WHO MNM tool (five disease-, four intervention- and seven organ dysfunction-based criteria). Main outcome measures were prevalence of MNM criteria and case fatality rates (CFR).

Results: A total of 3172 women were studied; 2538 (80.0\%) from the Netherlands, 248 (7.8\%) from Tanzania and 386 (12.2\%) from Malawi. Total SMO detection was 2767 (87.2\%) for disease-based criteria, 2504 (78.9\%) for intervention-based criteria and 1211 (38.2\%) for organ dysfunction-based criteria. Including every woman who received $\geq 1$ unit of blood in low-resource settings as life-threatening, as defined by organ dysfunction criteria, led to more equally distributed populations. In one third of all Dutch and Malawian maternal death cases, organ dysfunction criteria could not be identified from medical records.

Conclusions: Applying solely organ dysfunction-based criteria may lead to underreporting of SMO. Therefore, a tool based on defining MNM only upon establishing organ failure is of limited use for comparing settings with varying resources. In low-resource settings, lowering the threshold of transfused units of blood leads to a higher detection rate of MNM. We recommend refined disease-based criteria, accompanied by a limited set of intervention- and organ dysfunction-based criteria to set a measure of severity.
\end{abstract}

Keywords: Severe acute maternal morbidity, Maternal health, Maternal near miss, Maternal near miss-tool, World health organization, Delivery, Resource setting comparison, Organ dysfunction

\section{Background}

One of the Millennium Development Goals was to reduce global maternal mortality in 2015 by three quarters as compared to the level of 1990 [1]. In the summer of 2015, the United Nations reported an estimated 45\% decline (using data up to 2013), indicating that this target

\footnotetext{
* Correspondence: tom.witteveen@gmail.com

${ }^{1}$ Department of Obstetrics, Leiden University Medical Center, Albinusdreef 2, 2300 RC Leiden, the Netherlands

Full list of author information is available at the end of the article
}

would not be fully met. In the meantime, new Sustainable Development Goals have been set, including the reduction of the maternal mortality ratio below 70 per 100.000 live births by 2030 [2]. Assessment of pregnant women with severe maternal outcome (SMO), comprised of maternal near miss (MNM) and maternal death (MD), may contribute to accelerating this morbidity and mortality reduction [3].

The World Health Organisation (WHO) has defined a MNM as a 'woman who nearly died but survived a complication that occurred during pregnancy, childbirth or 
within 42 days of termination of pregnancy' [3, 4]. WHO proposes a 'MNM approach' to monitor and improve quality of obstetric care using a tool that classifies women according to several (potentially) life-threatening conditions (Table 1) [4]. The classification is based on three different types of criteria: disease-, interventionand organ dysfunction-based. If any of the organ dysfunction-based criteria are met, the MNM approach defines that case as 'life-threatening', and therefore MNM [5].

According to WHO, uniformity of this MNM classification should make it possible to compare the quality of obstetric care between different settings in different countries, which would be useful in improving health care delivery. However, in some low-resource settings application of the WHO MNM tool showed underreporting of life-threatening maternal morbidity. This may be due to lack of blood for transfusion, absence of laboratory diagnostics and poor clinical monitoring, which are all needed to identify MNM [6-8].

In a nationwide cohort, we previously found that also in the Netherlands, a high-resource setting, organ dysfunction-based criteria failed to identify almost $60 \%$ of women with severe acute maternal morbidities as MNM [9]. If these women, who were not detected as having had 'life-threatening' conditions, had attended obstetric care in low-resource settings the majority would likely have died.

Our previous studies have highlighted difficulties in finding universal criteria to identify MNM and raise questions about the applicability of the MNM tool in general, and its focus on organ dysfunction-based criteria in particular [6-9]. The objective of this study is to analyse merged data of one high- and two low-resource settings where this tool was applied and test whether the tool may be suitable for comparing SMO between these settings.

\section{Methods}

In this current study, we used merged data available from SMO databases collected in the Netherlands, Tanzania and Malawi. Data for the Netherlands were extracted from a two-year nationwide cohort study (the LEMMoN-study), for Tanzania from a two-year crosssectional study at Haydom Lutheran Hospital and for Malawi from a two-year study of maternal morbidity and mortality at Thyolo District Hospital (the '4 M-study'). A general description of the three study populations can be found in Table 1. Details and outcomes for these three cohorts have been published previously [7-10].

Women with SMO were included according to definitions established by the original studies (Table 2). We reassessed all cases in these three cohorts using
Table 1 WHO MNM tool groups and subcategories [4]

\begin{tabular}{|c|c|}
\hline Group A & Severe complications/potentially life threatening conditions \\
\hline $\mathrm{A} 0$ & Severe postpartum hemorrhage \\
\hline A1 & Severe pre-eclampsia \\
\hline$A 2$ & Eclampsia \\
\hline A3 & Sepsis or severe systemic infection \\
\hline A4 & Ruptured uterus \\
\hline Group B & Critical interventions or intensive care unit admission \\
\hline BO & Use of blood products (includes any blood transfusion) \\
\hline B1 & Interventional radiology (uterine artery embolization) \\
\hline B2 & Laparotomy (other than caesarean section) \\
\hline B3 & Admission to Intensive Care Unit \\
\hline Group C & Organ dysfunction/life-threatening conditions \\
\hline $\mathrm{CO}$ & $\begin{array}{l}\text { Cardiovascular dysfunction: Shock, cardiac arrest (absence } \\
\text { of pulse/ heart beat and loss of consciousness), use of } \\
\text { continuous vasoactive drugs, cardiopulmonary resuscitation, } \\
\text { severe hypoperfusion (lactate }>5 \mathrm{mmol} / \mathrm{l} \text { or }>45 \mathrm{mg} / \mathrm{dl} \text { ), } \\
\text { severe acidosis ( } \mathrm{pH}<7.1 \text { ) }\end{array}$ \\
\hline $\mathrm{Cl}$ & $\begin{array}{l}\text { Respiratory dysfunction: Acute cyanosis, gasping, severe } \\
\text { tachypnea (respiratory rate }>40 \text { breaths per minute), severe } \\
\text { bradypnea (respiratory rate }<6 \text { breaths per minute), } \\
\text { intubation and ventilation not related to anesthesia, severe } \\
\text { hypoxemia (O2 saturation }<90 \% \text { for } \geq 60 \text { min or } \mathrm{PAO} 2 / \mathrm{FiO} 2 \\
<200 \text { ) }\end{array}$ \\
\hline $\mathrm{C} 2$ & $\begin{array}{l}\text { Renal dysfunction: Oliguria non-responsive to fluids or } \\
\text { diuretics, dialysis for acute renal failure, severe acute azotemia } \\
\text { (creatinine } \geq 300 \mu \mathrm{mol} / \mathrm{ml} \text { or } \geq 3.5 \mathrm{mg} / \mathrm{dl} \text { ) }\end{array}$ \\
\hline $\mathrm{C} 3$ & $\begin{array}{l}\text { Coagulation/ hematologic dysfunction: Failure to form clots, } \\
\text { massive transfusion of blood or red cells }(\geq 5 \text { units), severe } \\
\text { acute thrombocytopenia ( }<50,000 \text { platelets } / \mathrm{ml})\end{array}$ \\
\hline C4 & $\begin{array}{l}\text { Hepatic dysfunction: Jaundice in the presence of } \\
\text { pre-eclampsia, severe acute hyperbilirubinemia (bilirubin } \\
>100 \mu \mathrm{mol} / / \text { or }>6.0 \mathrm{mg} / \mathrm{dl} \text { ) }\end{array}$ \\
\hline C5 & $\begin{array}{l}\text { Neurologic dysfunction: Prolonged unconsciousness } \\
\text { (lasting } \geq 12 \text { h)/coma (including metabolic coma), stroke, } \\
\text { uncontrollable fits/status epilepticus, total paralysis }\end{array}$ \\
\hline C6 & $\begin{array}{l}\text { Uterine dysfunction/ hysterectomy: Uterine hemorrhage } \\
\text { or infection leading to hysterectomy }\end{array}$ \\
\hline
\end{tabular}

the WHO MNM tool which defines MNM based on three different types of criteria: disease-, interventionand organ dysfunction-based. Fourteen cases $(0.4 \%)$ of the Dutch cohort were excluded due to insufficient data for application. All other 2538 SMO patients were assessed without the need for supplementation of any marker [9]. For the low-resource settings, identification of SMO did not only depend on relatively advanced laboratory tests, but could also happen on the basis of supplemented clinical markers as recommended by WHO [5].

Data from the three studies were collected into a single database containing the following variables: age $(<20$, 20-35 and $>35$ years), parity ( 0,1 and $\geq 2)$, units of blood given $(0,1,2,3,4$ and $\geq 5)$, duration of hospital stay, maternal mortality, and classification according to the three 
Table 2 Demographics of the three study populations

\begin{tabular}{llll}
\hline & The Netherlands & Tanzania & Malawi \\
\hline Study type & Prospective cohort & Prospective cohort & Prospective cohort \\
Period & $2004-2006$ & $2009-2011$ & $2007-2009$ \\
Population & Nationwide & Haydom Lutheran Hospital & Thyolo District \\
Maternity units & 98 & 1 & $29^{b}$ \\
Reference area $(\mathrm{km} 2)_{\text {Live births }^{\mathrm{a}}}$ & 41,526 & 51,000 & 1715 \\
Deliveries $^{\mathrm{a}}$ & 375,657 & 9136 & 31,838 \\
\hline
\end{tabular}

Data is shown in numbers

aDuring study period

Including Thyolo District Hospital and 28 smaller, government, mission and private facilities

WHO MNM tool criteria groups (disease-, interventionand organ dysfunction-based). If women had multiple conditions or interventions they were included into more than one criteria group, with each included criterion titled a separate 'event'. Case fatality rates (CFR) were calculated for the corresponding populations.

All parameters were compared between each country's population and those women who sustained lifethreatening conditions as per WHO definition. Outcomes for the three countries were analysed individually and compared for differences. Finally, the lifethreatening group was corrected by including every Tanzanian and Malawian woman (where giving five or more units is an exception even in life-threatening haemorrhage [11]) who received one unit or more of blood for transfusion. Maintaining five units of blood as an organ dysfunction criterion would imply that in settings where the availability of blood products is severely limited, fewer MNM cases are included.

Data were analysed using chi-square tests for categorical data and independent sample t-tests for numerical data. Statistical analysis was performed using SPSS statistics, version 20.0 (SPSS, Chicago, IL). All three initial studies had ethical approval and for present study anonymous data were used.

\section{Results}

A total of 3172 women were analysed: 2538 (80.0\%) from the Netherlands, 248 (7.8\%) from Tanzania, and 386 (12.2\%) from Malawi. General characteristics of all three populations are shown in Table 3. All parameters significantly differed between the three countries.

After assessment with the WHO MNM tool, out of the 2538 Dutch women, 2308 (90.9\%) fulfilled one or more disease-based criteria, 2116 (83.4\%) any intervention-based criterion and 1024 (40.3\%) any organ dysfunction-based criterion. In Tanzania there were 123 (49.6\%) women fulfilling disease-based, 231 (85.9\%) intervention-based, and 103 (41.5\%) organ dysfunctionbased criteria. For Malawi these numbers were 336
(87.0\%), 175 (45.3\%), and 84 (21.8\%), respectively. The detection in the combined study population of 3172 women was 2767 (87.2\%) women for disease-based, 2504 (78.9\%) for intervention-based, and 1211 (38.2\%) for organ dysfunction-based criteria. Only this final group sustained 'life-threatening conditions' according to WHO methodology. The CFRs were 48/2538 (1.9\%) for the Netherlands, 32/248 (12.9\%) for Tanzania and 46/ 386 (11.9\%) for Malawi. Of these maternal deaths, 17 (35\%) women in the Netherlands and 15 (33\%) women in Malawi could not be identified as having had a 'lifethreatening' condition. In Tanzania, all maternal deaths could be defined.

For the total population, analysis of the events detected by the WHO MNM tool subcategories is shown in Table 4. Postpartum haemorrhage (PPH) is the most commonly detected event among the disease-based criteria. Pre-eclampsia follows as an important second in the Netherlands, whereas in Tanzania and Malawi sepsis is more prominent. Giving blood products is the most frequent intervention and laparotomies (other than caesarean section) are more frequently performed in Malawi and Tanzania compared to the Netherlands. For the organ dysfunction-based criteria, coagulation or haematological dysfunction is the major reason for inclusion in the Netherlands, whereas in the low-resource settings this is cardiovascular dysfunction. Between countries all subcategories differed significantly except for the numbers of ruptured uterus (diseasebased), admissions to ICU (intervention-based), and women who presented with renal dysfunction or ended up having hysterectomy (organ dysfunctionbased).

Among women with life-threatening conditions (as defined by the organ dysfunction-based criteria, Table 5), PPH is the most common event for inclusion in the Netherlands and Tanzania. In Malawi $\mathrm{PPH}$, eclampsia, infection, and uterine rupture are almost equally represented. Eclampsia is significantly 
Table 3 Inclusion criteria of SMO used in the three study populations

\begin{tabular}{|c|c|c|}
\hline The Netherlands & Tanzania & Malawi \\
\hline $\begin{array}{l}\text { ICU admission } \\
\text { Admission to an ICU or coronary care unit, } \\
\text { other than postoperative recovery }\end{array}$ & $\begin{array}{l}\text { Clinical criteria } \\
\text { Acute cyanosis, gasping, respiratory rate } \\
>40 \text { or }<6 / \text { min, shock, oliguria non } \\
\text { responsive to fluids or diuretics, failure } \\
\text { to form clots, loss of consciousness } \\
\text { lasting }>12 \mathrm{H} \text {, cardiac arrest, stroke, } \\
\text { uncontrollable fit/total paralysis, jaundice }\end{array}$ & $\begin{array}{l}\text { Uterine rupture } \\
\text { Clinical symptoms or intrauterine foetal } \\
\text { death that led to laparotomy, at which } \\
\text { diagnosis was confirmed, laparotomy for } \\
\text { uterine rupture after vaginal birth, rupture } \\
\text { confirmed by autopsy or clinical symptoms } \\
\text { with high suspicion of rupture after death }\end{array}$ \\
\hline
\end{tabular}

Uterine rupture

Clinical symptoms that led to an emergency caesarean section, where uterine rupture was confirmed

Peripartum hysterectomy or laparotomy for uterine rupture

Eclampsia/HELLP

HELLP syndrome only when accompanied

by liver haematoma or rupture

Major obstetric haemorrhage $(\mathrm{MOH})$ Transfusion of $\geq 4$ units of packed cells Embolization or hysterectomy for $\mathrm{MOH}$ in the presence of pre-eclampsia

\section{Laboratory-based criteria}

Oxygen saturation $<90 \%$ for $\geq 60$ min

Acute thrombocytopenia $(<50,000$ platelets $/ \mathrm{ml})$

Eclampsia or severe pre-eclampsia with a maternal indication for termination of pregnancy

\author{
Management-based criteria \\ Admission to an ICU, hysterectomy following \\ infection or haemorrhage, transfusion of $\geq 1$ unit \\ of blood, intubation and ventilation $\geq 60 \mathrm{~min}$ \\ not related to anaesthesia, cardio-pulmonary \\ resuscitation \\ Severe maternal complications \\ Eclampsia, sepsis or severe systemic infection, \\ uterine rupture
}

\begin{abstract}
Major obstetric haemorrhage (including from complicated abortions and ectopic pregnancies)Transfusion of units of $\geq 450 \mathrm{ml}$ of blood or a haemoglobin level $<6 \mathrm{~g} / \mathrm{dl}$ measured after vaginal bleeding or estimated blood loss of $>1$ ।

Severe obstetric and non-obstetric peripartum infections

All infections for which iv antibiotics or iv anti-malarials were prescribed or surgical treatment was performed. Neoplasms resulting primarily from $\mathrm{HIV}$-infections
\end{abstract}

Other complication $\geq 2$ senior clinicians considered the condition as severe
Miscellaneous

SMO cases to the opinion of the treating

obstetrician, not to be included in

group 1-4

ICU intensive care unit, HELLP haemolysis elevated liver enzymes and low platelets, SMO severe maternal outcome

more common in both low-resource settings. Giving blood products is the commonest intervention-based criterion in the Netherlands and Malawi. In Tanzania this is ICU admission.

After correction for any blood transfusion in the lowresource settings the life-threatening group changed (Table 5). First, the MNM tool now identified 1458 (46.0\%) women with organ dysfunction, instead of 1205 (38.2\%). In addition, blood transfusion became a more frequent inclusion criterion in the low-resource settings as compared to the Dutch setting, and 'coagulation or hematologic dysfunction' was now equally represented in each setting. When including any blood transfusion, the position of $\mathrm{PPH}$ as major contributor to severe acute maternal morbidity becomes more prominent in Tanzania and Malawi (36.4\% and $24.4 \%$ raised to $53.2 \%$ and $42.6 \%)$.

The WHO MNM tool inclusions and general characteristics of women with life-threatening conditions (before and after correction for blood transfusion) can be seen in Tables 6 and 7. In comparison with the total study population (Table 3 ) higher CFRs are seen among women with life-threatening conditions, and among women in low-resource settings.

\section{Discussion}

Our results indicate that the WHO MNM tool, in its current form, is not useful for comparison between different resource settings. Detection differs between highand low-income countries and organ dysfunction-based criteria detect only $38.2 \%$ of all women with SMO as defined by the three cohort studies.

Moreover, in cases of maternal mortality and based on the specified criteria, organ dysfunction could not be identified from the medical records in 17 out of 48 cases (35\%) in the Netherlands and 15 out of 46 cases (33\%) in Malawi. We believe that a revision of the WHO MNM tool and specifically the organ dysfunction-based criteria is needed to enable meaningful comparison between different resource settings.

A recent study by Menezes et al. states that the WHO criteria perform well [12]. In this study, conducted in two Brazilian reference hospitals, 77 out of 1196 (6.4\%) women were identified as having lifethreatening conditions based on the WHO MNM tool, compared to $33.8 \%$ and $80.2 \%$ by using Waterstone's or other literature-based criteria respectively. However, the authors do not clarify why the other 
Table 4 Basic characteristics of total study population

\begin{tabular}{|c|c|c|c|c|}
\hline & Netherlands $(N=2538)$ & Tanzania $(N=248)$ & Malawi $(N=386)$ & $P$-value \\
\hline \multicolumn{5}{|l|}{ Age (y) } \\
\hline Data available & 2512 & 248 & 384 & \\
\hline$<20$ & $31(1.2)$ & $23(9.3)$ & $83(21.6)$ & b \\
\hline $20-35$ & 1945 (77.4) & $187(75.4)$ & $267(69.5)$ & a \\
\hline$>35$ & $536(21.3)$ & $38(15.3)$ & $34(8.9)$ & b \\
\hline \multicolumn{5}{|l|}{ Parity } \\
\hline Data available & 2388 & 227 & 377 & \\
\hline 0 & $1258(52.7)$ & $52(22.9)$ & $83(22.0)$ & b \\
\hline 1 & $867(36.3)$ & $30(13.2)$ & $56(14.9)$ & b \\
\hline$\geq 2$ & $263(9.9)$ & $145(63.9)$ & $238(63.1)$ & b \\
\hline \multicolumn{5}{|l|}{ Units of blood } \\
\hline Data available & 2461 & 248 & 371 & \\
\hline 0 & $734(29.8)$ & $64(25.8)$ & $201(54.2)$ & b \\
\hline 1 & $6(0.2)$ & $108(43.5)$ & $77(20.8)$ & b \\
\hline 2 & $88(3.6)$ & $54(21.8)$ & 65 (17.5) & b \\
\hline 3 & $50(2.0)$ & $12(4.8)$ & $19(5.1)$ & b \\
\hline 4 & $802(32.6)$ & $8(3.2)$ & $5(1.3)$ & b \\
\hline$\geq 5$ & $781(31.7)$ & $2(0.8)$ & $4(1.0)$ & b \\
\hline \multicolumn{5}{|l|}{ Mortality } \\
\hline Data available & 2538 & 248 & 386 & \\
\hline CFR & $48(1.9)$ & $32(12.9)$ & $46(11.9)$ & \\
\hline
\end{tabular}

Data is shown in numbers (percentage)

$\mathrm{a}=<0.05,{ }^{\mathrm{b}}=<0.0001$. CFR $=$ case fatality rate

1119 (93.6\%) women did not sustain MNM conditions or why these pregnant women did not 'nearly die, but survived' (according to WHO MNM definition). The reason for this omission appears that the current WHO criteria are mistakenly seen as the 'gold standard' for evaluation of severe maternal morbidity.

The underestimation of severe maternal outcome when applying the WHO MNM tool in its current form remains an important issue. Overall, diseasebased criteria show the highest detection of SMO (87.2\%) in each type of setting. An explanation for the low detection rate $(49.6 \%)$ in the Tanzanian population could be the local SMO criteria used in that study. For example, this led to fewer women with $\mathrm{PPH}$ (according to the WHO MNM definition of blood loss above one liter) in this cohort, as PPH as such was no separate inclusion criterion in the Tanzanian cohort (in contrast with Malawi) and women were only included if they had received blood transfusion. The intervention-based criteria detected $78.9 \%$ of all SMO cases. An explanation for the low detection $(45.3 \%)$ in the Malawian population is the absence of interventional radiology and an ICU. Both disease-based and intervention-based criteria show higher SMO detection in each setting compared to organ dysfunction-based criteria. The CFRs of the potentially life-threatening populations (fulfilling only disease-based criteria) in low-resource settings remain high (Tanzania 13/123, 10.6\%; Malawi 35/336, 10.4\% versus $23 / 2308,1.0 \%$ in the Netherlands). This implies that there is hardly any 'over-inclusion' in such settings and that these women should be picked up as SMO in the 'potentially life-threatening phase' of their conditions.

The lack of laboratory and clinical diagnostics for detecting organ dysfunction explains underreporting in low-resource settings [6-9]. Similar detection rates for Tanzania and the Netherlands may seem contradictory because advanced technology in the highly resourced Dutch setting would be expected to lead to a higher detection of SMO. An explanation could be found in the supplemented clinical criteria (such as acute cyanosis, gasping, loss of consciousness etc.) as part of the local Tanzanian inclusion criteria (Table 1). These compensate the lack of extensive 
Table 5 WHO MNM tool inclusions of the total study population

\begin{tabular}{|c|c|c|c|c|c|}
\hline \multirow{2}{*}{$\frac{\text { Category }}{\text { A: Disease }}$} & \multirow[t]{2}{*}{ Subcategory } & \multicolumn{4}{|l|}{ Events } \\
\hline & & Netherlands $(N=2638)$ & Tanzania $(N=139)$ & Malawi $(N=394)$ & $P$-value \\
\hline & $0: \mathrm{PPH}$ & $1635(62.0)$ & $66(47.5)$ & $110(27.9)$ & b \\
\hline & 1: Pre-eclampsia & $414(15.7)$ & $8(5.8)$ & $20(5.1)$ & b \\
\hline & 2: Eclampsia & $242(9.2)$ & $15(10.8)$ & $69(17.5)$ & b \\
\hline & 3: Sepsis & $118(4.5)$ & $30(21.6)$ & $148(37.6)$ & b \\
\hline & 4: Ruptured uterus & $229(8.7)$ & $20(14.4)$ & 47 (11.9) & 0.11 \\
\hline \multirow[t]{5}{*}{ B: Intervention } & & Netherlands $(N=3030)$ & Tanzania $(N=334)$ & Malawi $(N=224)$ & \\
\hline & 0: Blood products & $1743(57.5)$ & $184(55.1)$ & $165(73.7)$ & b \\
\hline & 1: Int. radiology & $111(3.7)$ & N/A & N/A & \\
\hline & 2: Laparotomy & $267(8.8)$ & $59(17.7)$ & $59(26.3)$ & b \\
\hline & 3: Admission to ICU & 909 (30.0) & $91(27.2)$ & N/A & 0.78 \\
\hline \multirow[t]{8}{*}{ C: Organ dysfunction } & & Netherlands $(N=1325)$ & Tanzania $(N=167)$ & Malawi $(N=96)$ & \\
\hline & 0: Cardiovascular & $166(12.5)$ & $60(35.9)$ & $35(36.5)$ & b \\
\hline & 1: Respiratory & $115(8.7)$ & $35(21.0)$ & $13(13.5)$ & b \\
\hline & 2: Renal & $26(2.0)$ & $4(2.4)$ & $1(1.0)$ & 0.21 \\
\hline & $3: \mathrm{C} / \mathrm{H}$ & $845(63.8)$ & $16(9.6)$ & $4(4.2)$ & b \\
\hline & 4: Hepatic & $27(2.0)$ & $3(1.8)$ & $11(11.5)$ & a \\
\hline & 5: Neurologic & $33(2.5)$ & $33(19.8)$ & $11(11.5)$ & b \\
\hline & 6: Hysterectomy & $113(8.5)$ & $16(9.6)$ & 21 (21.9) & 0.29 \\
\hline
\end{tabular}

Data is shown in numbers (percentage)

PPH postpartum haemorrhage, ICU intensive care unit, Int. radiology interventional radiology, $\mathrm{C} / \mathrm{H}$ coagulation/haematological, $\mathrm{N} / \mathrm{A}$ not applicable $\mathrm{a}=<0.05,^{\mathrm{b}}=<0.0001$

intensive care monitoring needed for detection by organ dysfunction-based criteria. This would also explain the low detection numbers in Malawi due to the mainly disease- and intervention-based local inclusion criteria.

Different criteria for SMO used in the three cohorts are the most important limitation of this study. SMO cases, as identified differently by local criteria, are being compared according to a single WHO MNM tool. The consequence may be an underestimation of SMO in low-resource settings as Tanzania and Malawi due to limited available diagnostics. However, this limitation also stresses the fact that application of the WHO MNM tool may differ in different contexts.

Another major issue is that, although WHO uses a threshold of five units, there is no consensus about the number of units of blood transfused, which identifies organ dysfunction [6-9]. After including every woman in a low-resource setting who received even one unit of blood, results show a more equally distributed 'life-threatening group' in all settings, emphasizing that the shortage of blood for transfusion remains a large problem in many low-resource settings [13]. Also, SMO detection rate increased from
$38.2 \%$ to $46.0 \%$ of all SMO cases. This $7.8 \%$ increase consists of 228 Tanzanian women (91.9\%) and 206 Malawian women (53.4\%). This leads to a more realistic comparison between high- and low-resource settings, because $\mathrm{PPH}$ is an important cause of SMO and lack of blood compounds this problem [11, 14]. Unfortunately, this is also due to unwillingness and impossibility of relatives to donate, and inadequacy or lack of blood bank storage facilities and transport $[6,7,11,15]$.

Although it is clear that there is an urgent need for monitoring health care delivery in both high- and low-resource settings, it remains difficult to determine which set of criteria should be used. In our opinion, disease-based criteria remain important in all settings, since detection rate is high and does not depend on local protocols. In contrast, for the same reason, intervention-based criteria (such as ICU admission) are of limited use. To prevent 'over-inclusion' for disease-based criteria, especially in high-income countries, more strict operational definitions (such as the blood loss threshold defining 'severe postpartum haemorrhage') are needed. For low-resource settings, supplemented clinical markers such as gasping, oliguria or jaundice could be included. Also, the 


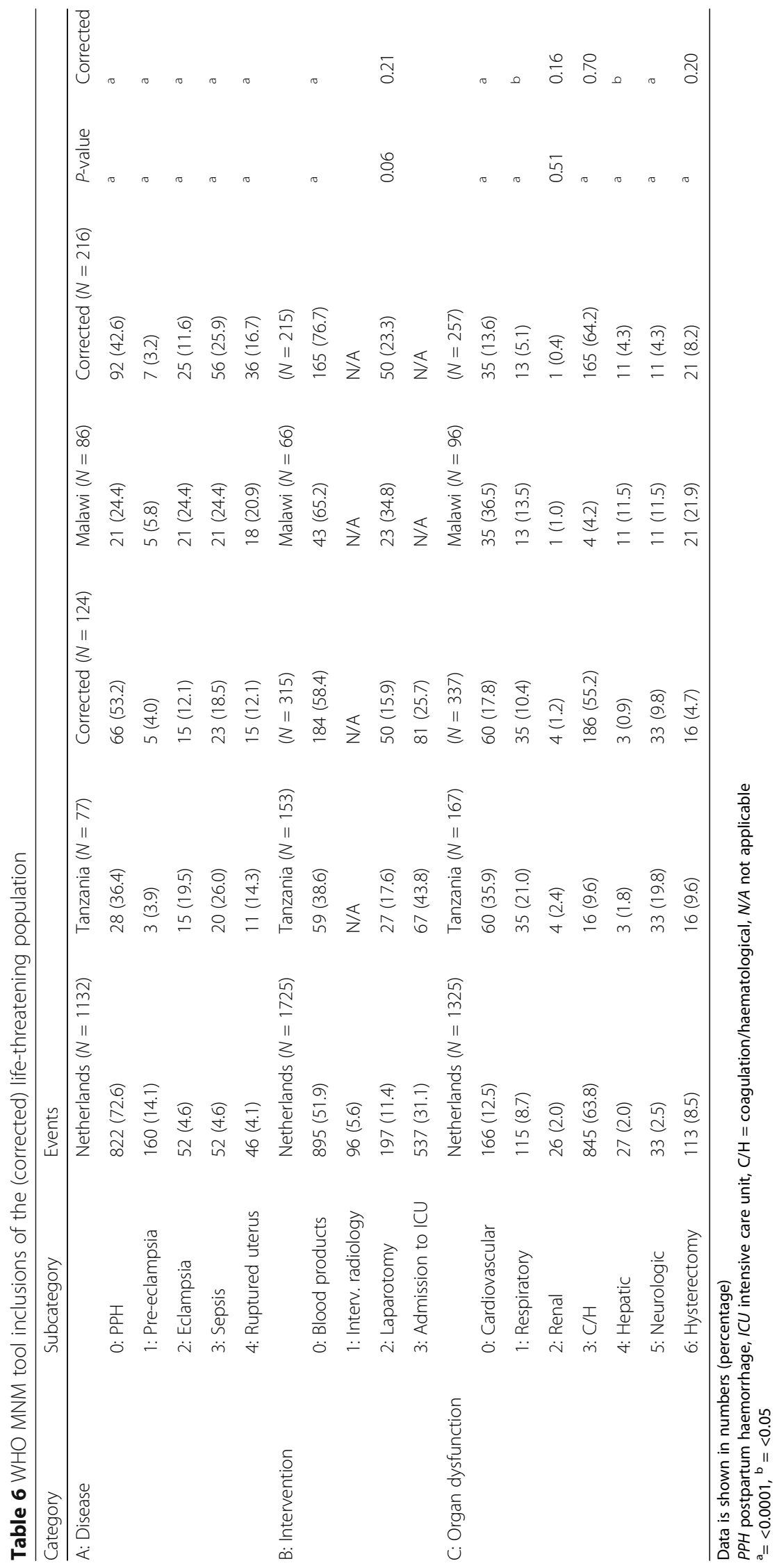


Table 7 Basic characteristics of the (corrected) life-threatening population

\begin{tabular}{|c|c|c|c|c|c|c|c|}
\hline & Netherlands $(N=1024)$ & Tanzania $(N=103)$ & Corrected $(N=228)$ & Malawi $(N=84)$ & Corrected $(N=206)$ & $P$-value & Corrected \\
\hline \multicolumn{8}{|l|}{ Age (y) } \\
\hline Data available & 1019 & 103 & 228 & 84 & 205 & & \\
\hline$<20$ & $11(1.1)$ & $15(14.6)$ & $22(9.6)$ & $16(19.0)$ & $29(14.1)$ & a & 0.15 \\
\hline $20-35$ & $760(74.6)$ & $75(72.8)$ & $170(74.6)$ & $54(70.2)$ & $157(76.2)$ & 0.71 & 0.69 \\
\hline$>35$ & $248(24.3)$ & $13(12.6)$ & $36(15.8)$ & $9(10.7)$ & $19(9.2)$ & a & b \\
\hline \multicolumn{8}{|l|}{ Parity } \\
\hline Data available & 967 & 93 & 208 & 81 & 202 & & \\
\hline 0 & $514(53.2)$ & $28(30.1)$ & $47(22.6)$ & $19(23.5)$ & $32(15.8)$ & a & 0.08 \\
\hline 1 & $333(32.5)$ & $10(10.8)$ & $27(13.0)$ & $9(11.1)$ & $28(13.6)$ & a & 0.79 \\
\hline$\geq 2$ & $120(12.4)$ & $55(59.1)$ & $134(64.4)$ & $53(65.4)$ & $142(70.3)$ & a & 0.21 \\
\hline \multicolumn{8}{|l|}{ Units of blood } \\
\hline Data available & 1000 & 103 & 228 & 82 & 202 & & \\
\hline 0 & $123(12.3)$ & $44(42.7)$ & $44(19.3)$ & $39(47.6)$ & $49(24.3)$ & a & 0.21 \\
\hline 1 & $6(0.6)$ & $22(21.4)$ & $108(47.4)$ & $14(17.1)$ & $64(31.7)$ & a & c \\
\hline 2 & $23(2.3)$ & $25(24.3)$ & $54(23.7)$ & $17(22.1)$ & $62(30.7)$ & a & 0.10 \\
\hline 3 & $16(1.6)$ & $6(5.8)$ & $12(5.3)$ & $5(6.1)$ & $17(8.4)$ & a & 0.19 \\
\hline 4 & $88(8.8)$ & $4(3.9)$ & $8(3.5)$ & $3(3.7)$ & $5(2.5)$ & 0.07 & 0.53 \\
\hline$\geq 5$ & $744(74.4)$ & $2(1.9)$ & $2(0.9)$ & $4(4.9)$ & $4(2.0)$ & a & 0.33 \\
\hline \multicolumn{8}{|l|}{ Mortality } \\
\hline Data available & 1024 & 103 & 228 & 84 & 206 & & \\
\hline CFR & $31(3.0)$ & $32(31.1)$ & $32(14.0)$ & $21(25.0)$ & $28(13.6)$ & & \\
\hline
\end{tabular}

Data is shown in numbers (percentage)

CFR case fatality rate

$\mathrm{a}=<0.0001,{ }^{\mathrm{b}}=<0.05,{ }^{\mathrm{c}}=<0.01$

threshold of received units of blood should be lowered for organ dysfunction-based criteria [8].

\section{Conclusions}

In conclusion, we have shown that applying solely organ dysfunction-based criteria may lead to underreporting of SMO. Therefore, a tool based on defining MNM only upon establishing organ failure is of limited use for comparing settings with varying resources. It is important to enact the discussion and eventually reach consensus for a tool that is usable in all resource settings and detects the highest percentage of the actual rate of SMO. We recommend refined disease-based criteria, accompanied by a limited set of (intervention- and organ dysfunctionbased) criteria to set a measure of severity. We believe that with these adjustments, the MNM tool may be more valuable and could ultimately lead to more comparable assessments of the quality of obstetric health care across different settings.

\section{Additional file}

Additional file 1: Details of local ethics committees. (DOCX 62 kb)

\section{Abbreviations}

CFR: Case fatality rate; ICU: Intensive care unit; MD: Maternal death; MNM: Maternal near miss; PPH: Postpartum haemorrhage; SMO: Severe maternal outcome; WHO: World health organisation

\section{Acknowledgements}

The authors would kindly like to thank all local staff and coordinators from all hospitals participating (all 98 Dutch hospitals, Haydom Lutheran Hospital and Thyolo District Hospital) for reporting women who were included in the three cohort studies used in this study.

\section{Funding}

No funding was used for this study.

\section{Availability of data and materials}

Data is available from the corresponding author on reasonable request.

\section{Authors' contributions}

$T W, K B, J R$ and TA were responsible for the main study concept and design, to which all authors provided additional contributions. HB, IK, EN and TA acquired the data. TW, HB and IK performed the statistical analysis. All authors actively participated in interpreting the results and revising the paper. All authors read and approved the final version for publication.

Competing interests

JR is a Section Editor for BMC Pregnancy and Childbirth. The authors declare that they have no competing interests.

Consent for publication Not applicable. 


\section{Ethics approval and consent to participate}

In this study only anonymous data are used and information cannot be related to individual women. The local ethical committees have approved all cohort studies that are used. Full name and affiliations of the local committees can be found in the Additional file 1.

\section{Publisher's Note}

Springer Nature remains neutral with regard to jurisdictional claims in published maps and institutional affiliations.

\section{Author details}

'Department of Obstetrics, Leiden University Medical Center, Albinusdreef 2, 2300 RC Leiden, the Netherlands. ${ }^{2}$ Department of Obstetrics and Gynaecology, North Bristol NHS Trust, Southmead Hospital, Westbury-on-Trym, Bristol BS10 5NB, UK. ${ }^{3}$ Wilhelmina Children's Hospital Birth Center, University Medical Center Utrecht, Lundlaan 6, 3584 EA Utrecht, the Netherlands. ${ }^{4}$ Athena Institute, VU University Amsterdam, De Boelelaan 1085, 1081 HV Amsterdam, the Netherlands.

Received: 13 July 2016 Accepted: 5 June 2017

Published online: 19 June 2017

\section{References}

1. WHO. Achieving Millennium development goal 5: target $5 \mathrm{~A}$ and $5 \mathrm{~B}$ on reducing maternal mortality and achieving universal access to reproductive health. Geneva: WHO reference number: WHO/RHR/09.06; 2009.

2. United Nations. 'The Millennium Development Goals Report 2015' and 'Transforming our world: the 2030 agenda for sustainable development. ' New york, 2015. [http://www.un.org/]. Accessed 18 Oct 2015.

3. Souza JP, Gulmezoglu AM, Vogel J, Carroli G, Lumbiganon P, Qureshi Z, et al. Moving beyond essential interventions for reduction of maternal mortality (the WHO Multicountry survey on maternal and newborn health): a cross-sectional study. Lancet. 2013;381:1747-55.

4. World Health Organization, Department of Reproductive Health and Research. Evaluating the quality of care for severe pregnancy complications. Geneva: The WHO near-miss approach for maternal health; 2011. p. 1-1.

5. Say L, Souza JP, Pattinson RC. Maternal near miss-towards a standard tool for monitoring quality of maternal health care. Best Pract Res Clin Obstet Gynaecol. 2009;23:287-96.

6. Van den Akker T, Beltman J, Leyten J, Mwagomba B, Meguid T, Stekelenburg J, et al. The WHO maternal near miss approach: consequences at Malawian District level. PLoS One. 2013;8:e54805.

7. Van den Akker T, van Rhenen J, Mwagomba B, Lommerse K, Vinkhumbo S, van Roosmalen J. Reduction of severe acute maternal morbidity and maternal mortality in Thyolo District, Malawi: the impact of obstetric audit. PLoS One. 2011;6:e20776.

8. Nelissen E, Mduma E, Broerse J, Ersdal H, Evjen-Olsen B, van Roosmalen J, et al. Applicability of the WHO maternal near miss criteria in a low-resource setting. PLoS One. 2013;8:e61248.

9. Witteveen $T$, de Koning I, Bezstarosti $H$, van den Akker $T$, van Roosmalen J, Bloemenkamp KW. Validating the WHO maternal near miss tool in a high-income country. Acta Obstet Gynecol Scand. 2015; epub ahead of print

10. Zwart JJ, Richters JM, Ory F, de Vries JI, Bloemenkamp KW, van Roosmalen J. Severe maternal morbidity during pregnancy, delivery and puerperium in the Netherlands: a nationwide population-based study of 371,000 pregnancies. BJOG. 2008;115:842-50.

11. Bates I, Chapotera GK, McKew S, van den Broek N. Maternal mortality in sub-Saharan Africa: the contribution of ineffective blood transfusion services. BJOG. 2008;115:1331-9.

12. Menezes FEF, Galvão LPL, de Mendonça CMM, Gois KA, Ribeiro RF, Santos VS, et al. Similarities and differences between WHO criteria and two other approaches for maternal near miss diagnosis. Tropical Med Int Health. 2015;20:1501-6.

13. Beltman J, van den Akker $T$, van Lonkhuijzen $L$, Schmidt $A$, Chidakwani R, van Roosmalen J. Beyond maternal mortality: obstetric hemorrhage in a Malawian district. Acta Obstet Gynecol Scand. 2011;90:1423-7.
14. Hendriks J, Zwart JJ, Briët E, Brand A, van Roosmalen J. The clinical benefit of blood transfusion; a hypothetical case-control study based on a nationwide survey of severe maternal morbidity. Vox Sang. 2013;104:234-9.

15. Kongnyuy EJ, Mlava G, van den Broek N. Facility-based maternal death review in three districts in the central region of Malawi: an analysis of causes and characteristics of maternal deaths. Womens Health Issues. 2009;19:14-20.

\section{Submit your next manuscript to BioMed Central and we will help you at every step:}

- We accept pre-submission inquiries

- Our selector tool helps you to find the most relevant journal

- We provide round the clock customer support

- Convenient online submission

- Thorough peer review

- Inclusion in PubMed and all major indexing services

- Maximum visibility for your research

Submit your manuscript at www.biomedcentral.com/submit
) Biomed Central 